\title{
Automatic Water Tank Filling System with Water Level Indicator
}

\author{
G. M. Barbade, Chandurkar Shreyas, Shounak Vedant, Nimkar Vaibhav, Patil Umesh
}

\begin{abstract}
In this project, we have worked with an indicator on an automatic water level controller. When we looked up our topic on the internet, we realized that most of the projects used microcontrollers or IC 555, but we didn't include any of these circuits in our model. Our design is based on the LM324N IC, which functions as a rectifier, oscillator, and comparator. On this foundation, we construct our circuit, and our model is successfully executed at a minimal cost.

The project's goal is to conserve water. Water is a necessary component of our daily life. Water plays a vital role in our everyday life since there is not any water we can't imagine in our lives. Water is essential for digestion and plays some important roles in the body, such as waste removal, body temperature control, and nutrient transport. Our daily lives began in the upper tank that is the most crucial part of all the houses. Water in your house, including drinking, cooking, bathing, cleaning, and washing, is used almost for all purposes. Appliances such as washing machines and scrubbers require continuous flow. Inhouse, overhead tanks comply with those requirements. As a result, saving water for humans is important.

This problem can be solved by using an automatic water level controller and indicator. The water level controller's operation is based on the fact that water conducts electricity due to the minerals in it. So As a result, the circuit can be opened or closed using water. The various circuits in the control unit send out different signals as the water level rises or falls. These signals are used to turn ON or OFF the motor pump depending on our requirements. I'm going to install an automatic water level controller so we don't have to manually turn the motor $O N$ and OFF. The unit tracks the water level and then activates the relay, which activates the Motor. The LM324N IC, carbon level sensor, and relay are the key components in this unit. With this project, we will be able to automatically monitor water wastage and maintain water levels in various systems, such as water tanks, boilers, swimming pools, and so on. Water and energy losses are reduced as a result of this. This also saves manpower because it is no longer necessary to run it manually.
\end{abstract}

Keywords: Save Water, Automatic, level Controller, Integrated Circuit, Control, Level Sensor.

Manuscript received on 03 June 2021 | Revised Manuscript received on 10 June 2021 | Manuscript Accepted on 15 September 2021 | Manuscript published on 30 September 2021. * Correspondence Author

Mr. G. M. Barbade, Professor, Department of Electrical Engineering, Government Polytechnic, Nanded, India. Email: 27ganeshgp@gmail.com

Mr. Shreyas Narendra Chandurkar*, Student, Department of Electrical Engineering, Government Polytechnic, Nanded, India. Email: chandurkarshreyas@gmail.com

Mr. Vedant Shudhakar Shounak, Student, Department of Electrical Engineering, Government Polytechnic, Nanded, India. Email: shounakvedant@gmail.com

Mr. Vaibhav Ram Nimkar, Student, Department of Electrical Engineering, Government Polytechnic, Nanded, India. Email: vaibhavnimkar85@gmail.com

Mr. Umesh Balaji Patil, Student, Department of Electrical Engineering, Government Polytechnic, Nanded, India. Email: umeshpatilb03@gmail.com

(C) The Authors. Published by Lattice Science Publication (LSP). This is an open access article under the CC-BY-NC-ND license (http://creativecommons.org/licenses/by-nc-nd/4.0/)

\section{INTRODUCTION}

The everyday routine begins with water. This is one of the basic survival needs. People depend on the upper reservoir for everyday use. The upper tank is made of an opaque or cement (concrete) material to prevent algae growth and is closed with a cap to protect from dust and mosquito infestation. So, the level of water in the tank is unknown. Oftentimes, we turn on the motor and forget to turn it off, because of this most of the water will be lost unknowingly. This leads to water scarcity.

Therefore, there is a need for a replacement that can start automatically, and shut off the motor when the water is filled to the desired level.

Automatic water level controllers are a product created to automatically control the motor, which helps to ensure that there is a constant reserve of water in the storage tank. These automatic water level controllers are used to automatically fill the overheadtank when it starts up or when it becomes empty and also monitor the water level in it.

Automatic water level controllers start the motor when the water level drops below a certain level and turn off the motor when the water rises above a fixed level. The motor will also shut off when the sump water runs out before it fills the upper tank, or if the pump is dry and also maintains voltage fluctuations. These are the latest products based on advanced digital technology. This system is Versatile. There are also custom variations such as controlling multiple pumps or multiple tanks. The carbon water level sensor provides contact water level measurement.

The system for controlling water levels is an electronic device that controls the operation of the water pump in subterranean and overhead storage tanks when electrically connected to the starting point of any pump assembly motor. Switches ON the pump assembly when the water level in the overhead tank falls below the preset level, Switches OFF the pump mount if the water level in the top tank is fully supplied, OFF switches the pump mounting when the underground tank is of low water levels, Switches ON Pumping group if the tank has enough water.

The automatic system for regulating the water level is a technical project. It can automatically switch on and off the domestic water pump set according to the water level of the reservoir. You can implement this driving pattern at your home or college using less expensive components.

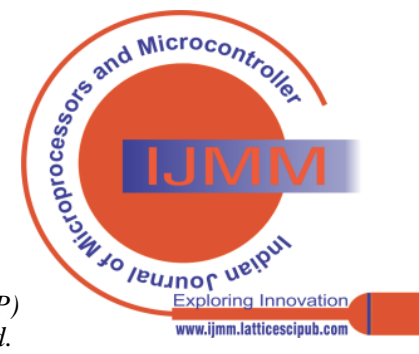


The most important advantage of this circuit is that it automatically operates the water pump without any user interaction. The Auto Pump Controller eliminates the need for any manual switching of the pumps installed to pump water from one reservoir to another reservoir. If the water level in the tank falls below a certain low level and the water level in the reservoir is above a certain level, it immediately turns on the pump. As the water level in the tank filled to an upper level (M), the pump was automatically turned off. Only when the water level in the tank falls below the level in the tank, and the level in the reservoir is above R, is the pump turned back on. This automated process is still going on.

Automatic controls on the water level can help to minimize energy use by controlling motor functions. This significantly reduces the amount of water and energy loss. The motor will also prevent drying out and ensure its longevity.

\section{ANNOTATED BIBLIOGRAPHY}

\section{Automatic Water Level Control System (International Journal of Science and Research[1]}

The better way of software and hardware architecture that blends for interfacing purposes was exposed in this research paper, which includes designing and developing an automated water level control system. To detect the water level, the device uses advanced sensing technology. It controls the motor with an Arduino and a relay. At the Beaker's various junctions, separate wires are connected. When we fill the beaker with water. The water makes contact with the wire, which indicates the tank's water level. As a result, the level of water has been reflected on an LCD. The motor is turned on and off with the aid of a relay.

Design and Development of Automatic Water Flow Meter (International Journal of Computer Science, Motoring and Applications [2]

Hemant Lenka and his team based their research on the importance of water level controllers in irrigation in agriculture. According to the article, each crop needs a particular amount of water, which can be achieved by using an automated water level controller, which would also help to reduce water waste. They employ a technique to determine the rate of water flow in irrigation pipelines. It measures the rate of flow with a Hall Effect Sensor. The G1/2 Hall Effect water flow sensor is a sensing device that contains a turbine rotor whose speed varies depending on the rate of water flow.

\section{Automatic Water Level Controller with Short Messaging Service (SMS) Notification (International Journal of Scientific and Research Publications)[3]}

Anuj Pathak and his colleagues present an automated water level controller with SMS notification in this research paper. Water can be maintained by users during load shedding thanks to the addition of SMS notifications to the automatic controller system. The automatic level controller and the SMS system function together in a synergistic way. The software was created in the Arduino programming environment and then transferred to the Microcontroller. The system's water level is automatically maintained. Battery power is used to run the controller. The user receives an SMS notification whenever the device detects an empty level and the status of load shedding. The process will be automated by installing a single sensor device in the tank that will take water level measurements regularly and power the motor automatically. This device removes the need for people to fill the tank regularly and monitors for leakage.

\section{Automated Multiple Water Tanks Control System Using ATMEGA and FPGA Technology, IEEE [4]}

ATMEGA328, ultrasonic sensor, buzzer, and Xilinx were used to design the device. Three tanks, each with its own set of ultrasonic sensors, were used in the experiment. The controller was an Arduino board. When the machine was turned on, water flowed through tank 1st, indicating that tank 2nd had been filled and the buzzer had been activated to show that two or more tanks had been filled. Following that, tank 3rd was filled before the level indicator controller detected it, at which point the water supply was turned off. As a result, there was no water waste. Xilinx ISE was used to build and implement the same on FPGA. In comparison to microcontrollers, FPGA has proved to be more beneficial for automating multiple water tanks.

"Non-contact Water Level Monitoring System Implemented Using LabVIEW and Arduino," 2017 International Conference on Recent Advances in Electronics and Communication Technology[5]

An Arduino UNO, an ultrasonic sensor, and a pump are included in the proposed model. An ultrasonic sensor was used to determine the water level. There was a link between the Arduino and the LABVIEW software. The Arduino turned on and off the pump based on the sensor readings, and the water was filled into the tank, as shown on the LABVIEW front screen. If there is no water in the lower tank and the pump is turned on, the pump will be disabled and energy will be lost. This is because the ultrasonic sensor is only mounted in the upper tank, not the lower tank.

Design And Implementation Of Wireless Based Water Level Monitoring Using Arduino And Bluetooth, International Research Journal of Motoring And Technology[6]

The water level sensor, buzzer, and water pump were used to create the prototype. The controller received the water level sensed by the sensor, which was then passed to the Bluetooth module, which then transmitted the information to the registered mobile. Additionally, a buzzer was used as a signal. When exposed to a damp atmosphere, the sensor is of the touch form, with a measurement range of just $4 \mathrm{~cm}$ and a short lifetime. Having power applied to the probe continuously speeds up the rate of corrosion dramatically.

IoT - Mobile Enabled Smart Water Level Controlling System To Regulate Water Wastage[7]

An Arduino microcontroller, a water level sensor and a cell phone were used to create the prototype. The controller received the level of water sensed by the water level sensor and updated the information to the server. The cell phone received the information stored on the server.

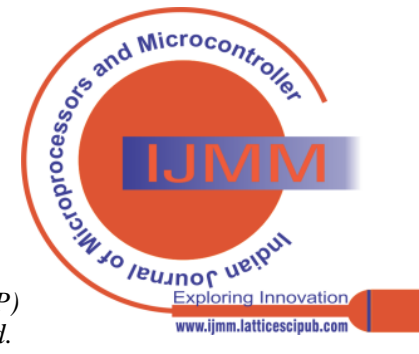


By working the buttons on the mobile, the user decides whether to turn on or off the motor. The contact-type sensor is used. When exposed to moisture, the measurement range is small and the lifetime is short. Intervention by humans is needed.

Multilevel Water Level Control\& Monitoring of Multiple Tanks, International Journal of Advances in Scientific Research and Motorering[8]

The float switches, 89S52 microcontroller, an ESP8266 Wi-Fi module were used to build the prototype. Four tanks were taken in this operation. The sensing factor was afloat. The data was sent to the ESP8266 Wi-Fi module, which will upload to the server. Water level sensors and motor driver circuits were controlled by the microcontroller. A total of 16 float switches are used in the system. The contact type float switches are easily stuck and do not move; they have poor accuracy and precision, and they require regular maintenance.

"Design of intrinsically safe intelligent water-level monitor used in a coal mine ", IEEE Trans. on Industrial Applications [9]

The most recent solution, as explained, is to use an image sensor to measure water levels. Unlike other types of sensors, it can provide information about the environment around the sensor as well as the water level, allowing the measured data to be verified. It also has the benefit of not being influenced by the weather. Commenting on his encounters with the radar sensor and the surrounding area. We've been really happy with this sensor because it was simple and easy to mount, and we haven't had to touch it in over five months, according to Rikk Smith.

Microcontroller based Automatic Water level Control System, International Refereed Journal of Motorering and Science[10]

The module consists of hardware and software to control the operation of pumping water in an overhead tank storage system. It can determine the presence of water in the tank, turn on/off the pump, and view the status on an LCD screen. Through using a calibrated circuit to show the water level and using DC instead of AC power, this research has successfully enhanced existing water level controls, reducing the risk of static shock.

\section{Automatic Water Level Sensor and Controller System [11]}

This paper has established a method that uses a level detector to measure the availability of water in the tank and then changes the state of the water pump based on the information obtained by the level detector. A seven-segment monitor and a motor pump are employed in this model. A water level sensor and a digital logic processor circuit are included in the proposed system. The proposed system removes the need to manually regulate water use in homes and agricultural areas.

Water Level Monitoring System using IoT, International Research Journal of Motorering and Technology[12]

The system proposed in this paper is a basic water level monitoring system with multiple stages indicated. It also indicates when the water level falls below or rises above the required level. This method allowed us to better understand how Bluetooth modules work and how they can be used to create a portable device.

Smart Wireless water level Monitoring \& Pump controlling System, International Journal of Advances in Scientific Research and Motorering[13]

This paper describes a device that uses ultrasonic sensors to determine the depth of water. A water level indicator, a water level sensor, a water pump control system, and a microcontroller are all included in the system. The ultrasonic sensor detects the presence of water, sends a signal to the microcontroller, and the pulses begin to echo.

\section{AIM AND OBJECTIVES}

The intended device's goal or aims are to create an automatic water level management system with automatic control. In this project, sensors are placed at various levels of the tank, and the integrated circuit uses these sensors to monitor the level of the liquid at any given time. The following are some of the objectives:

$\checkmark$ Develop a control system for water level control in the tank.

$\checkmark$ Check the tank's water level. The motor begins when the water level falls below or is extinguished, depending on the level of the water. If it's complete.

$\checkmark$ Display of the water level, as output, and other important information on LEDs.

$\checkmark$ Monitor the tank water level, i.e. the engine turns on when the level inside the tank is low and vice versa

\section{TECHNICAL APPRAISAL OF PROJECT}

\section{A. Working principle}

Carbon sensor works on the principle of the law of conductivity without electrical contact which means when water touches the carbon sensor then there is no current flow through it but the carbon sensor create a sensing pulse and trigger the LED light to Turn ON and send a signal to Turn OFF an automatic submersible pump after the water tank has been refilled and back to the water level control circuit.

\section{B. Methodology}

There have been several approaches to constructing an automatic water level control with a switching device, but all of them require human intervention. This project uses electrical control to build an automatic water level control system with a switching device for both overhead and underground tanks to replace the water without human intervention. When the water tank falls below a certain level, the system turns off the electric pump and shuts down the water pump. When the tank is full, the system turns off the electric pump and shuts down the water pump. The overall design was subdivided using function block diagrams. Each block in the diagram represents a section of the circuit that performs a specific function.

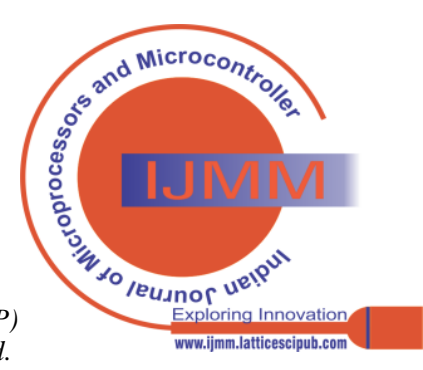


The system was built using functional blocks, as shown in the block diagram. In this manner, the circuit is designed to display two separate levels by utilizing three sensors to monitor the inflow of water in the tank. These panels, however, can be increased or decreased depending on the amount of resolution required. To accomplish this, increase or decrease the number of level detectors and associated components. The system is powered by a $9 \mathrm{~V}$ step-down transformer using full-wave diodes, and sequential correction output is filtered using a condenser. The final design schematic block diagram for the method is shown in the figure below.

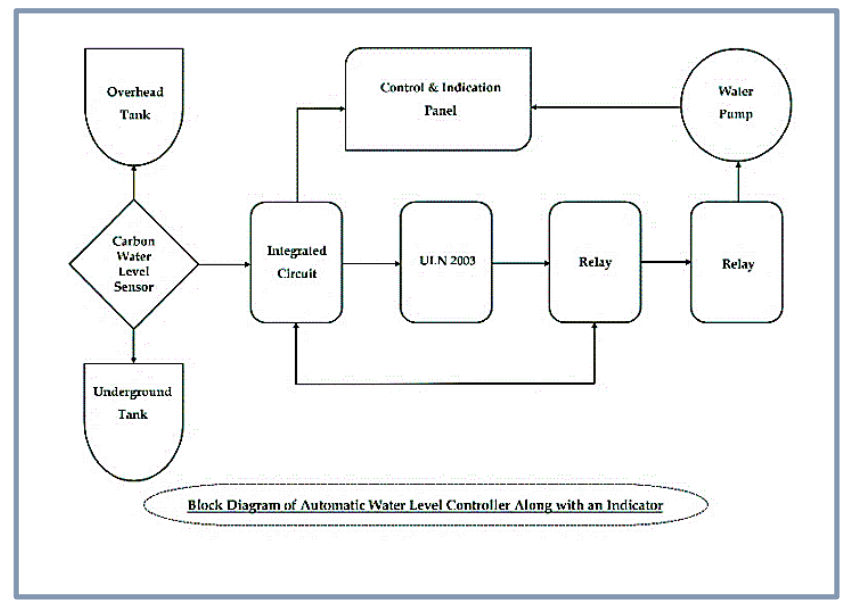

Figure No. 1: Block Diagram of Automatic Water Tank Filling System Along with an Indicator

\section{Circuit illustration}

The circuit consists of six BD139 transistors, each with $100 \mathrm{~K}$-ohm resistance at the base, and serves for the rest of the circuit as a current limiting resistor. The emitter of both the overhead and underground water tanks' middle and upper transistors is then connected to a $47 \mathrm{~K}-\mathrm{ohm}$ resistor, while the lower sensors transistor of both transistors is connected to the IC LM324N. All of the underground tank's emitters, as well as those on the overhead, are shorted, as seen in the positive and negative sign box, which is installed after the bridge circuit with VCC set to 9 VDC.

In addition, for turning on and off the motor, the relay input side is connected to the emitter of a half-level transistor, and the output side is connected parallel to LEDs, as shown in the figure. Two switches are connected before the motor for manual and automated motor starting, as shown in the diagram. Switch S2 is connected between the relay's N/C contacts and the motor, while another N/C and N/O are connected parallel to the LED across the emitter.

Similarly, the DC voltage is treated first by a bridge rectifier circuit built from an IN4007 diode following the 230/12-volt transformer's O/P, even if an LED coupled in parallel to $180 \mathrm{~K}$-ohm is employed to signal whether the motor is on or off in another relay. The relay will work in both scenarios if a diode is placed in front of it for freewheeling purposes, meaning that a connection will be formed within it.

The pump motor is started when the water level in the above tank falls below a preset level and is turned off when the water level rises over the full level since the circuit is entirely automated. Carbon sensors A and B are situated at the tank's full and half-filled levels, respectively. The letter $\mathrm{C}$ is found near the bottom of the tank. The transistors Q1,
Q2, and Q3 make up the level-sensing part of the circuit. Carbon sensors A and B open when the water level goes below half, but transistors Q1 and Q2 remain off. The necessary transistors are biassed and turn on when the water level rises to the point where the Carbon sensors are contacted. Resistors R1, R2, R3 limit the base current of matching transistors, while resistors R4, R5 restrict the collector current.

The LEDs D1 and D2 make the live water level apparent. Carbon sensor $\mathrm{C}$ is at the bottom of the tank, whereas carbon sensors $\mathrm{A}, \mathrm{B}$, and $\mathrm{C}$ are at the top, half, and bottom of the tank, respectively. The circuit's level-detecting section, i.e. the carbon sensor, is built around transistors Q1, Q2, and Q3. Carbon sensors A, B, and C open when the water level goes below half, but transistors Q1, Q2, and Q3 remain switched off. The matching transistors are biassed and turn on when the water level rises to the point where the probes are contacted. Resistors R1, R2, R3 limit the base current of matching transistors, while resistors R4, R5 restrict the collector current.

LEDs D1 and D2 are used to show the current water level. Transistor Q2 switches off and the collector of the transistor becomes positive when the water level falls below half. The collector of transistor Q2 is connected to the base of transistor Q3, causing transistor Q3 to turn on. Transistor Q6 will be ON since its base is connected to Q6's collector, which is currently off. As a result, when the water level goes below the medium relay RL, the pump is activated. Because the relay is wired in latching mode, the pump will continue to run even if the water level increases above half full, ensuring that the tank is filled.

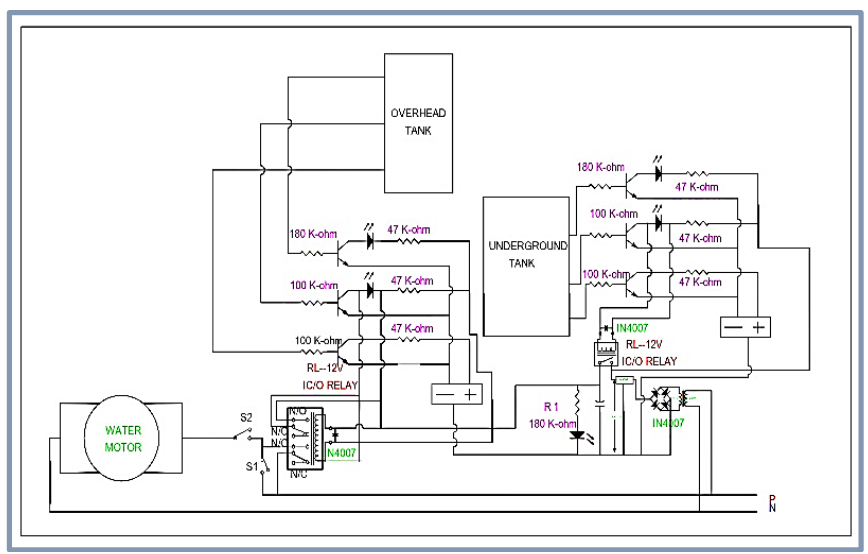

Figure No. 2: Circuit Diagram

In latching mode, the relay is wired with a single pair of $\mathrm{N} / \mathrm{O}$ contacts. When the relay is activated, these contacts close, resulting in a short between Q6's collector and emitter. As a result, the status of Q6 does not affect the relay's operation, and the relay remains active as long as transistor Q5 is turned on.

Turning off Q5, which happens automatically when the water level reaches its maximum level, is the sole way to switch off the relay. IC1's trigger pin (pin2) is linked to the collector of transistor Q1. Transistor Q1 switches on when the water level reaches its maximum.

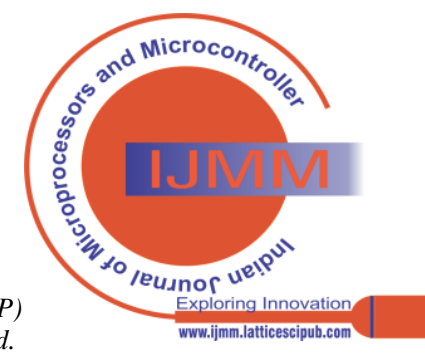


As a result, the IC1's collector connects to the ground, causing the monostable IC1 to be triggered. The output of IC1 increases for about a second. This simultaneously turns on transistor Q4 and turns off transistor Q5, whose base is connected to Q4's collector, effectively turning off the relay's power source. This turns the motor off and keeps it off until the water level falls below the medium level.

Resistor R8 pulls up the BC547's trigger pin. Capacitor C3 connects the collector of Q1 to the BC547 trigger pin when the transistor Q1 is turned on, allowing edge triggering. A monostable circuit can be edge triggered by connecting the trigger signal to the trigger input pin via a capacitor. The capacitor keeps DC out of the circuit while still enabling fast changes to get through. The circuit is named negative edge triggered because the monostable is triggered whenever the trigger input signal falls. R10 and R12 limit the collector currents of Q4 and Q5, whereas R9 and $\mathrm{R} 11$ restrict the base currents.

\section{Working Methodology}

The circuit for this project involves three-carbon sensors, one for underground and one for overhead, which is linked to carbon sensors in water at various levels to determine the volume of water in the tank. In terms of the lower, upper, and middle level.

As shown in the circuit design, two LED indicators are coupled to three BD139 transistors. The requisite resistors have been installed in both the LEDs and the transistors. Carbon sensors are made from single-stranded wires with short lengths. A double pole double throw (DPDT) relay switch is connected to a transistor. An IN4007 diode is used to wire the relay switch. The relay switch's generally closed terminal is connected to a motor, allowing it to run until the common pole is changed to the ordinarily open terminal. When $9 \mathrm{~V}$ is applied to the circuit and $12 \mathrm{~V}$ is applied to the relay switch, a small current flows to the base of the transistor through the resistor as soon as the water in the tank reaches the carbon sensor, i.e. As a result, the transistor conducts, causing the LED to brighten, trying to signal that the water has been filled to the required level.

When water comes into touch with the carbon sensor, a little current runs through the BD139 transistor's base and the resistor

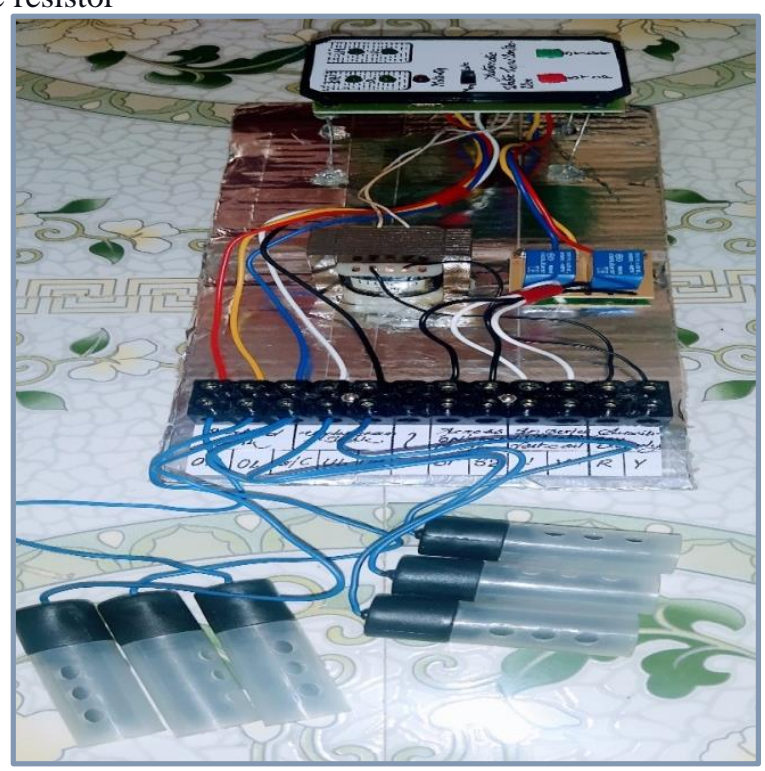

Figure No. 3: Connected Hardware in Simple Manner
In series with it. When the water reaches the carbon sensor, the process is repeated for all three levels. When the water reaches the top carbon sensor, the motor is immediately turned off, resulting in a relay, which means that a small current is generated when the water in the tank comes into touch with the carbon sensor's detecting component.

The transistor conducts, as a result, causing the LED to light and showing that the tank is full, and the pole of the relay switch turns from normal to reverse. The motor is disconnected from the circuit and stops functioning when the switch is changed from closed to generally open. After the tank has been filled, this ensures that no water is wasted.

\section{SPECIFICATIONS}

This automatic water level controller has the following specifications:

$\checkmark$ This model has a dry run prevention feature, which means it will only turn on the motor if there is water in the underground tank or sump.

$\checkmark$ Because our controller is unloaded, it is suitable for any single-phase motor. The load is passed on to the existing starter.

$\checkmark$ A motor on/off LED indicator is included.

$\checkmark$ For both tanks, there is a water level indicator.

$\checkmark$ There is an option to choose one of auto and manual mode.

$\checkmark$ In Auto Mode, the motor will start and stop on its own.

$\checkmark$ In manual mode, the user can start and stop the motor by pressing the controller's start and stop buttons.

$\checkmark$ No manpower is required because the controls are fully automated from the underground tank to the overhead tank.

$\checkmark$ Long service life.

\section{MARKET FORECAST}

For the following reasons, the market potential of this water level indicator is quite great.

A. Circuitry that is basic- A simple circuit makes up this water level indicator automated as user-friendly.

B. Cost-effective- The circuit's essential equipment is easily obtainable and is inexpensive.

C. Environment friendly- The production process for this item has no impact on the environment.

D. Easily accessible- As whole assembled work is easy to install and ready to use

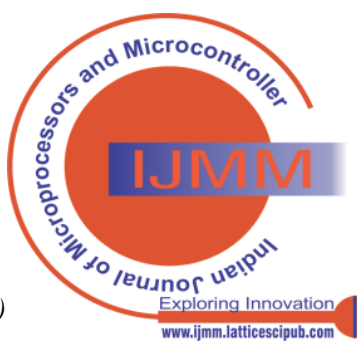


VII. SNAPSHOTS AND PHOTOS

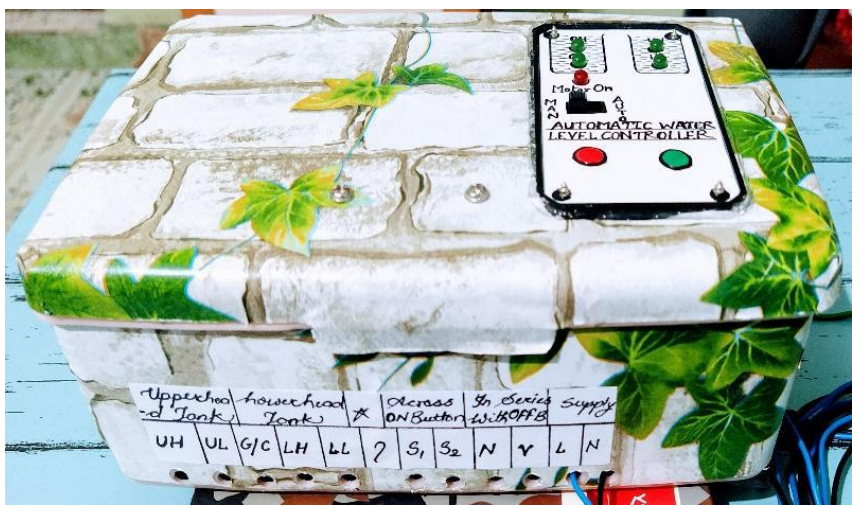

Figure No. 4: Panel Looking View of Model

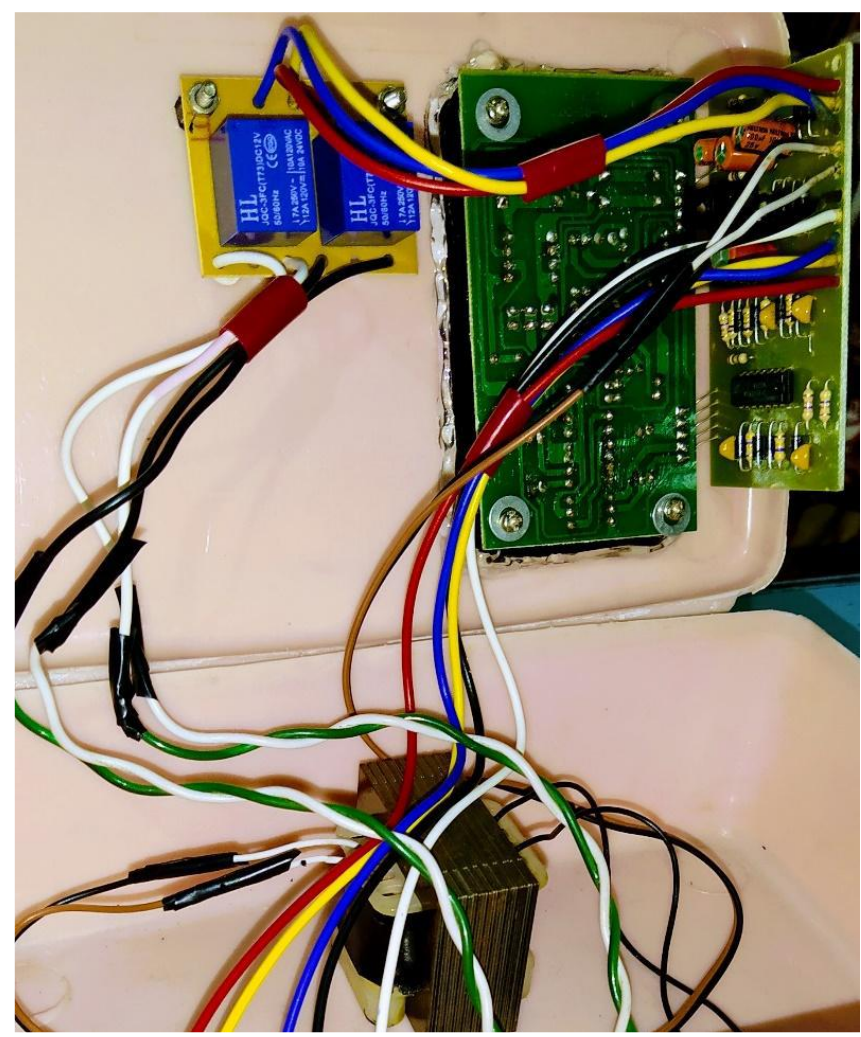

Figure No. 5: Circuit View of Model

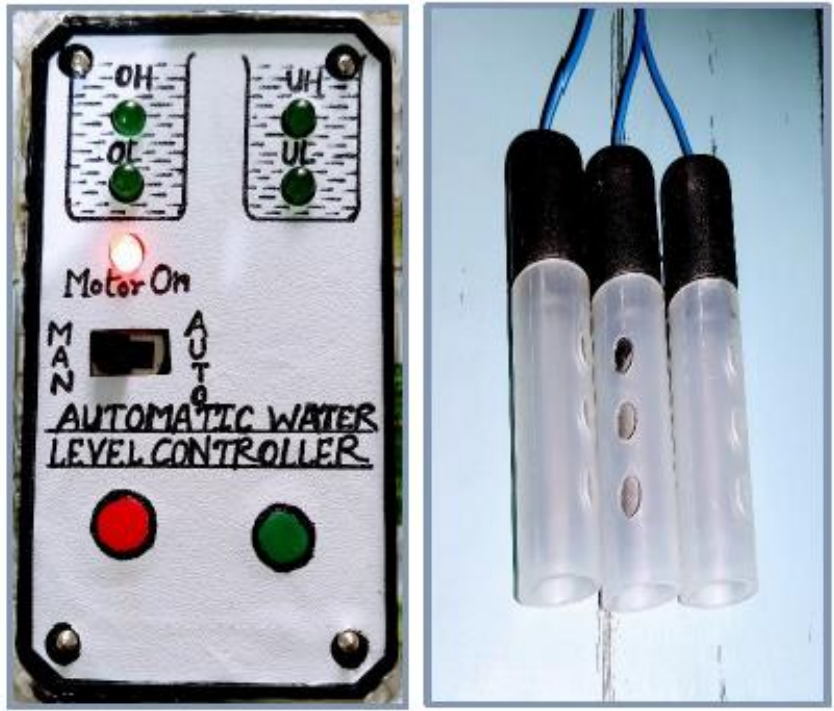

Figure No. 6: Control \& Indication Panel with Carbon Water Level Sensor

\section{FINDINGS}

Following our research into several journal articles, we have discovered that there are numerous methods for creating this water controller module. We can easily make a module that is both inexpensive and efficient by using a complex circuit. Based on our studies, we noticed that most of the project makers are focused on a microcontroller or an IC 555. Due to excessive waste of water in domestic and industrial areas, we have realized that this module is very important in both areas. So, since our goal is that the average person can afford it, we make our project very productive and low in cost.

\section{OBSERVATION}

To reduce human interference and save time, the automation of various components around us has been greatly increased. The water tank overflows because the tank's water level cannot be determined at random. This results in increased energy demand, which is currently a major issue. People must also wait until the tank is full before proceeding with their other activities. As a result, here is an idea for a sensor that detects and shows the water level, allowing the pump to be turned off at the appropriate time, saving water, electricity, and time. Hence the "Automatic Water Level Controller along with Indicator by using any appropriate element" project can become very useful on a large scale due to the low manpower requirements and the ease of implementation, making it more accessible to all.

\section{RESULT}

When water touches the carbon sensor that the carbon sensor creates a sensing pulse and triggers the LED light to Turn ON and send a signal to Turn OFF an automatic water pump after refilled the water tank and back to the water level control circuit.

Due to the carbon level sensor signal and relay operation, the output of these data reveals that the tank is filled by reaching Level 3 in the water tank, which instantly cuts the motor off.

\section{CONCLUSION\&FUTURE SCOPE}

The goal of this article was to construct a basic automatic water level monitor and controller that was low-cost and easy to use. This can be used to monitor the levels of various liquids and oils in corporations and chemical labs, as well as water tanks. We used a transistor as a basis for this system, which was coupled to a relay, as well as low-cost local components. We aimed to design a system that would have widely available components and when coupled, would reduce water waste. The system is completely automated. As a result, it does not necessitate professional support. It's not prohibitively expensive. With this technique, future research and development will be a lot easier. Although it is a project, we anticipate that with some modification, a fair range of applications will emerge.

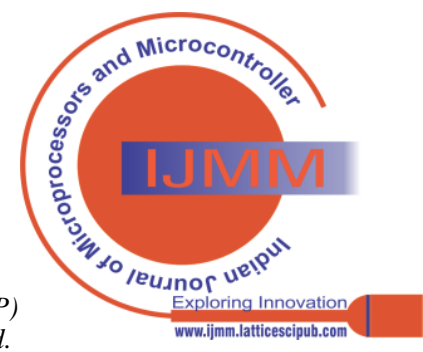


The project's primary goal is to develop a system that is customizable, cost-effective, and simple to set up to reduce water loss. A web-based water level monitoring and control system for home automation could be constructed soon, allowing the system to be managed from anywhere using the internet and a mobile phone. A GSM module can be used to send SMS messages with the current status to registered mobile phones. It may be customized and used in some situations, including preventing highly hazardous liquid spills in chemical plants and other natural disasters.

\section{REFERENCES}

1. Asaad Ahmed Mohammedahmed Eltaieb, Zhang Jian Min,"Automatic Water Level Control System", China - Tianjin

2. Ria Sood, Manjit Kaur, Hemant Lenka, "Design and Development of Automatic Water Flowmeter", Mohali, India

3. Sanam Pudasaini, Anuj Pathak, Sukirti Dhakal, Milan Paudel,"Automatic Water Level Controller with Short Messaging Service (Sms) Notification", Kathmandu University, Nepal

4. Lukman Adewale Ajao, Blessing Olatunde Abisoye, James Agajo,Abdulzeez Olorundare Ajao, Muhammed Bashir Muazu, Abdulazeez Femi Salami, Automated Multiple Water Tanks Control System Using Atmega And Fpga Technology, Ieee Mac 2019, Pp 347-353.

5. R. M. Shrenika, S. S. Chikmath, A. V. R. Kumar, Y. V. Divyashree And R. K. Swamy, "Non-Contact Water Level Monitoring System Implemented Using Labview And Arduino," 2017 International Conference On Recent Advances In Electronics And Communication Technology (Icraect), Bangalore, 2017, Pp. 306-309. [CrossRef]

6. Teetla Asha, Vidadala Srija, Design And Implemntation Of Wireless Based Water Level Monitoring Using Arduino And Bluetooth, International Research Journal Of Motorering And Technology (Ijert), Volume: 07, Issue: 01| Jan 2020.

7. Siddartha Shankar, Dr M Dakshayini, Iot-Mobile Enabled Smart Water Level Controlling System To Regulate Water Wastage, 2018 Ieee, Pp 2045-2048. [CrossRef]

8. Shandong Jianzhu "Design Of Intrinsically Safe Intelligent WaterLevel Monitor Used In Coal Mine ", Ieee Trans. On Industrial Applications, Vol. 19, Pp.1052 -1056 1983

9. K. Santhosh Kumar, G. Mukesh, K. Deepti, Microcontroller Based Automatic Water Level Control System, International Refereed Journal of Motorering And Science (Irjes) Volume 4, Issue 11, November 2015.

10. Beza Negash Getu and Hussain A. Attia, Automatic Water Level Sensor and Controller System, Â@2016 Ieee.

11. Teetla Asha, Vidadala Srija, Design And Implemntation Of Wireless Based Water Level Monitoring Using Arduino And Bluetooth, International Research Journal Of Motorering And Technology (Ijert), Volume: 07, Issue: 01| Jan 2020.

12. Priya J, Sailusha Chekuri, Water Level Monitoring System Using Iot, International Research Journal Of Motorering And Technology (Irjet) Volume: 04 Issue: 12, Dec-2017.

13. Madhurima Santra, Sanjoy Biswas, Sibasis Bandhapadhyay And Kaushik Palit, Smart Wireless Water Level Monitoring \& Pump Controlling System, International Journal Of Advances In Scientific Research And Motorering (Ijasre), Vol. 03, Issue 4, May -2017.

\section{AUTHORS PROFILE}

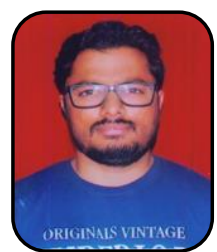

Mr. G. M. Barbade, is a lecturer in the Department of Electrical Engineering at the Government Polytechnic Nanded.He graduated from VJTI in Mumbai with a master's degree in power systems. He has two years of professional experience in the industrial sector.And also He worked for a year in a research organisation. In this project, His involved as a mentor and educator, he helped to ensure that connections and accurate system configuration follow the control module.

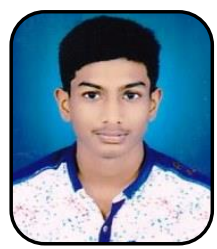

Mr. Shreyas Narendra Chandurkar, is in his last year of Electrical Engineering at the Government Polytechnic, Nanded.From the Government Industrial Training Institute, he obtained a vocational diploma in electrician.He aspires to work in developing new technologies and thus is interest in microprocessor innovation, circuit analysis, and digital control
systems.This project gave him the opportunity to make a significant contribution to a current research, working for a year and contributing as circuit assembly, as well as making the overall connection and designing the model. Since this is his first research project, he has not yet published anything.

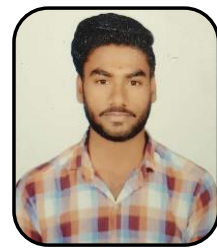

Mr. Nimkar Vaibhav Ram, is a final-year Electrical Engineering student at Government Polytechnic Nanded. He worked as a member for a year, collecting the necessary components and data for the 'Automatic water tank filling system with water level indicator.'He looked back at previous reports and journals to see how intricate the relations were, as well as evaluating content data for references to make the model more efficient.

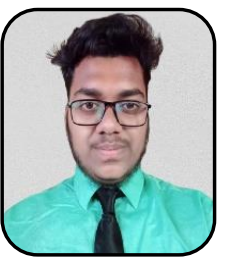

Mr. Vedant Sudharkar Shounak, is in his final year of Electrical Engineering at Government Polytechnic, Nanded.Power systems programming, creative and sustainable power systems, and power systems are only a few of the research topics that are of interest. Because this is his first research project, this is my first opportunity to engage with IJMM lattice science through a research study on "Automatic water tank filling system with water level indicator."He worked for a year on this project, testing circuit performance and the appropriate use of components utilised in its construction, as well as the fabrication of a model and its successful use.

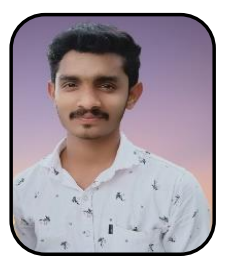

Mr. Umesh Balaji Patil, a third-year Electrical Engineering student, has been working on this project for a year and is interested in control systems, electromechanics, and electrical materials research. I acquired essential material, such as research articles for reference, and executed required duties while working in a group. In addition, there was further work that needed to be done.

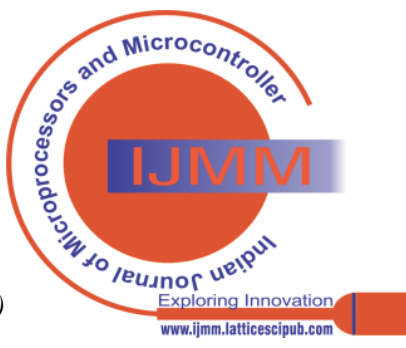

